\title{
AVALIAÇÃO DO CRESCIMENTO DE PLANTAS DE MILHO EM FUNÇÃO DE DOSES DE POTÁSSIO E ESTRESSE HÍDRICO(1)
}

\author{
E. F. VILELA ${ }^{(2)} \&$ L.T. BÜLL ${ }^{(3)}$
}

\begin{abstract}
RESUMO
Este trabalho teve por objetivo estudar o efeito de variações nas doses de potássio e nos níveis de estresse hídrico sobre o ajustamento osmótico e crescimento de plantas de milho (Zea mays L.). Para tanto, instalou-se um experimento em vasos que continham $40 \mathrm{dm}^{3}$ de Terra Roxa Estruturada Latossólica textura média argi losa, em casa de vegetação telada do Departamento de Ciência do Solo, Campus de Botucatu, UNESP/SP, de dezembro de 1994 a fevereiro de 1995. $O$ delineamento experimental utilizado foi o de blocos ao acaso em esquema fatorial ( $2 \times 3 \times 3)$. Os tratamentos consistiram da aplicação de duas doses ( 35 e $130 \mathrm{mg} \mathrm{dm}^{-3}$ ) de potássio na forma de $\mathrm{KCl}$ e três condições de estresse hídrico, sendo plantas sem estresse (SO) e plantas que sofreram estresse hídrico moderado (S1) ou intenso (S2), 44 dias após a emergência. 0 crescimento das plantas foi avaliado em três épocas, aos 55, 69 e 83 dias da emergência. Da análise geral dos resultados pôde-se inferir que as fol has das plantas de mi lho se ajustaram osmoticamente com relação as doses de potássio, em condições de estresse hídrico moderado. Não houve efeito dos estresses hídricos na acumulação de $\mathrm{K}$, Ca e Mg nas folhas; no entanto, a maior dose de $\mathrm{K}$ aplicado ao solo proporcionou, em todas as épocas, maior teor deste nutriente e menores de Ca $\mathrm{e}$ de Mg nas folhas. Os níveis de estresse utilizados não influíram na área foliar, mas o maior teor de água no solo aumentou a produção de matéria seca das partes e, principalmente, da planta toda, mostrando ser esta última a melhor característica para avaliação do déficit de água na planta. A maior dose de $\mathrm{K}$ proporcionou maior área foliar e produção de matéria seca às partes e à planta toda; no entanto, não influenciou o comportamento de nenhum índice fisiológico estudado. 0 maior teor de água no solo mostrou menores valores de área foliar específica (AFE), razão de área foliar (RAF) e razão de massa foliar (RMF). A adição de potássio não melhorou o crescimento da cultura, quando o fornecimento de água foi limitado. No entanto, as plantas mais bem nutridas em potássio produziram mais massa, independentemente dos níveis de água utilizados, indicando melhor produção de matéria seca destas plantas.
\end{abstract}

Termos de indexação: ajustamento osmótico, análise de crescimento, matéria seca, índices fisiológicos.

(1) Parte da Tese de Doutorado apresentada pelo primeiro autor, para obtenção do título em Agronomia, a Faculdade de Ciências Agronômicas, FCA/UNESP, Botucatu (SP). Recebido para publicação em setembro de 1997 e aprovado em janeiro de 1999.

(2) Professor Adjunto do Departamento de Engenharia, Universidade Federal de Lavras. Caixa Postal 37, CEP 37200-000 Lavras (MG).

(3) Professor Titular do Departamento de Ciência do Solo, FCA/UNESP. Caixa Postal 237, CEP 18603-970 Botucatu (SP). Bolsista do CNPq. 


\title{
SUMMARY: EVALUATION OF MAIZE GROWTH AS A FUNCTION OF POTASSIUM RATES AND WATER STRESS
}

\begin{abstract}
The objective of this research was to evaluate the effects of potassium rates and water stress levels on the growth of maize (Zea mays, L.) plants. A pot $\left(40 \mathrm{dm}^{3}\right)$ experiment was carried out using a "Terra Roxa Estruturada Latossólica", an Alfi sol intergradeto Oxisol, clayey loam soil, in Botucatu - São Paulo, Brazil, from December 1994 to F ebruary 1995. Theexperimental design was a randomized bl ock with a $(2 \times 3 \times 5)$ factorial distribution of the treatments. Two potassium rates ( 35 and $130 \mathrm{mg} \mathrm{dm}^{-3}$, as $\mathrm{KCl}$ ) and three water stress levels were studied: no water stress (S0), moderate (S1) and intense (S2) levels, from the $44^{\text {th }}$ day after emergence. All pots were irrigated to maximum soil water potentials ($0,0106 \mathrm{MPa}$ ) when the soil water potentials reached $-0,0232,-0,0484$ and $-1,5 \mathrm{MPa}$ for the S0, S1 and S2 treatments, respectively. Plant growth was evaluated during five periods, being thefirst at 27 days after emergenceand each 14 days thereafter. Theosmotic adjustment in leaves was measured using the vol ume-pressure technique. Thel eaves exhibited osmotic adjustment to potassium level s under moderated water stress. Therewereno effects of applied water stress level s on the contents of $\mathrm{K}, \mathrm{Ca}$ and $\mathrm{Mg}$ in thel eaves; however, thehighest rate of potassi um promoted thehighest concentration of this nutrient and the lowest of $\mathrm{Ca}$ and $\mathrm{Mg}$ for all periods. Thewater stress levels did not affect thel eaf area; however, thehighest water level in soil increased the dry matter of all the components and mainly of the whole plant, the latter being the best parameter to evaluate water deficits. Potassi um increased the leaf area, but did not affect any of thestudied physiological indices. Water stress increaseled to a decrease of the specific leaf area, leaf area rate and leaf matter rate. Potassium did not improve plant growth with limited water supply. However, those plants best supplied with potassium showed the highest mass production, regardless of the applied water levels, suggesting improved crop production.
\end{abstract}

Index terms: osmotic adjustment, growth analysis, dry matter, physi ol ogical indices.

\section{INTRODUÇÃO}

Na região dos cerrados, é comum a ocorrência de estiagem (veranicos) que varia de 5 a 10 dias na parte oeste e até 25 dias na parte leste do País, durante o período chuvoso (Assad et al., 1993). Geralmente, esse veranico atinge as culturas em sua fase reprodutiva, e o estresse hídrico compromete a produção final.

Normalmente, as plantas que sofrem estresse hídrico têm maiores concentrações de solutos nos tecidos e menores potenciais osmóticos do que plantas supridas comágua adequadamente. Quando a el evação de concentrações de solutos não é apenas o resultado da desidratação do tecido, o fenômeno é conhecido como ajustamento osmótico, sendo considerado benéfico à planta, pois permite que as células das plantas retenham mais água a reduzidos potenciais de água no solo (Sharp et al., 1990).

Quando a planta está sujeita a estresse hídrico, muitos de seus processos fisiológicos são afetados, tais como: abertura estomática, fotossíntese, síntese de proteínas, atividade enzimática e hormonal, dentre outros. Resultados de pesquisa têm apontado o potássio como importante regulador osmótico, pela influência que exerce no decréscimo do potencial osmótico da planta e na prevenção da perda de água (Premachandra et al., 1991; Andersen et al., 1992).

Apesar de overanicoser um dos fatores que mais restringe a produção do milho no B rasil, poucos têm sido os estudos que correlacionam as respostas das plantas à fertilidade do solo e, principalmente, à adubação potássica, visando mi nimizar o efeito deste sobre a produtividade da cultura.

No presente trabalho, plantas de milho foram cultivadas sob duas doses de potássio e submetidas a três níveis de estresse hídrico, aplicados durante a fase reprodutiva da cultura, com o objetivo de determinar o efeito da adubação potássica e do estresse hídrico sobre o ajustamento osmótico das fol has e sobre o crescimento das plantas de milho, bem como avaliar a resposta das diversas partes da planta como características indicadoras de deficiência hídrica.

\section{MATERIAL E MÉTODOS}

O experimento foi realizado com ohíbrido demilho Braskalb XL678, em casa de vegetação telada, no Departamento de Ciência do Solo-UNESP - Campus 
de Botucatu (SP), no período de dezembro/1994 a fevereiro/1995. Os tratamentos consistiram da aplicação de duas doses de potássio na forma de KCl ( 35 e $130 \mathrm{mg} \mathrm{dm}^{-3}$ de K) e três condições de estresse hídrico: plantas sem estresse (S0) e plantas que sofreram estresse hídrico moderado (S1) ou intenso (S2), a partir dos 44 dias da emergência (DAE). A coleta de dados das plantas foi realizada em três épocas: 55, 69 e $83 \mathrm{DAE}$. O delineamento experimental utilizado foi o de blocos ao acaso, em esquema fatorial de $2 \times 3 \times 3$, com três repetições, totalizando 54 vasos.

Foi utilizada amostra deTerra Roxa Extruturada Latossólica textura média argilosa (EMBRAPA, 1988) no enchimento dos vasos (40 dm³). Amostras com 480, 100 e $420 \mathrm{~g} \mathrm{~kg}^{-1}$, respectivamente, deareia, silte e argila, e densidade global de $1,42 \mathrm{~g} \mathrm{~cm}^{-3}$. As análises químicas iniciais eapós cal agem eadubação do sol o estão expressas no quadro 1.

A quantidade de calcário aplicada por vaso foi calculada com base no método de Raij \& Quaggio (1983). O solofoi incubado com doses correspondentes a 4,64 t ha-1 (93 g/vaso) de calcário dolomítico (PRNT $=95 \%$ ), eas doses de potássio, a um nível de umidade de 0,21 $\mathrm{g} \mathrm{g}^{-1}$ base em massa de sol o seco, 42 dias antes da semeadura. A pós esse período, cada tratamento foi suplementado com $270 \mathrm{mg} \mathrm{kg}^{-1} \mathrm{deP}$, utilizando-se $130 \mathrm{~g}$ de superfosfato simples e $65 \mathrm{~g}$ de termofosfato Yoorin BZ. As adubações nitrogenadas, na forma de solução aquosa, foram feitas na dose de $20 \mathrm{mg} \mathrm{dm}^{-3}$, aplicadas aos 16, 29, 46 e 56 DAE, como sulfato de amônio, uréia, sulfato de amônio e uréia, respectivamente.

No dia 03/12/94, foram semeadas 12 sementes de milho por vaso, deixando-se duas plantas no desbaste, efetuado aos $14 \mathrm{DAE}$, quando a planta apresentava três fol has totalmente desenvolvidas. N esta época, foi instalado um tensiômetro em cada vaso, à profundi dade de $10 \mathrm{~cm}$, entreas duas plantas, para medição do potencial matricial deágua no solo. Os tensiômetros foram construídos de acordo com Vieira \& Castro (1987).

Quadro 1. Análise química das amostras do solo original e após calagem, adubação básica e aplicação de duas doses de potássio

\begin{tabular}{|c|c|c|c|c|c|c|c|c|}
\hline Amostra & $\begin{array}{c}\mathrm{pH} \\
\mathrm{H}_{2} \mathrm{O}\end{array}$ & M.O. & $\begin{array}{c}\mathbf{P} \\
\text { resina }\end{array}$ & $\mathbf{K}^{+}$ & $\mathrm{Ca}^{2+}$ & $\mathrm{Mg}^{2+}$ & CTC & V \\
\hline & & $\mathrm{g} \mathrm{dm}^{-3}$ & $\mathrm{mg} \mathrm{dm}^{-3}$ & 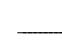 & $-\mathrm{mmol}$ & ${ }_{c} \mathrm{dm}^{-3}$ & - & $\%$ \\
\hline $\mathrm{T}$ & 4,8 & 20 & 4 & 0,4 & 10 & 2 & 70 & 17 \\
\hline $\mathrm{K}_{1}$ & 6,5 & 19 & 138 & 1,4 & 58 & 22 & 104 & 78 \\
\hline $\mathrm{K}_{2}$ & 6,5 & 20 & 95 & 3,8 & 50 & 19 & 98 & 74 \\
\hline
\end{tabular}

$\mathrm{T}=$ solo original; $\mathrm{K}_{1}=35 \mathrm{mg} \mathrm{dm} \mathrm{m}^{-3}$ de $\mathrm{K} ; \mathrm{K}_{2}=130 \mathrm{mg} \mathrm{dm}^{-3}$ de $\mathrm{K}$.
Utilizaram-se, no controle da irrigação, dados da curva característica de umidade do solo, determinada por placas porosas de tensão e tensiometria. Até os $44 \mathrm{DAE}$, quando se iniciou a diferenciação dos níveis de estresse hídrico, todos os tratamentos foram irrigados a uma faixa de umidade entre -0,0106 e -0,0232 MPa. O tratamento S0 foi desenvolvido dentro desta faixa de umidade até a coleta final. Os tratamentos S1 eS2 foram irrigados a potencial máximo deágua no sol o de-0,0106 MPa, ea rega subseqüente só ocorria a potenciais de água no solo de -0,0484 e -1,5 MPa, respectivamente. O monitoramento do teor de água no sol o foi feito por tensiometria nos tratamentos $\mathrm{SO}$ eS1 e, notratamento S2, pela medição do potencial de água na fol ha em plantas murchas, ao amanhecer. Dos 44 aos 77 DAE, foram aplicados setee quatro ciclos deestresse hídrico para os tratamentos S1 e S2, respectivamente.

Para avaliar a possível ocorrência deajustamento osmótico nas fol has de plantas de milho, utilizou-se o método pressão-volume, descrito por Tyree \& Hammel (1972). Os potenciais osmóticos foram determinados aos 77 DAE. No dia anterior à medição dos potenciais, o vaso foi saturado com água, e a planta foi coberta com um saco plástico, para que adquirisse máxima turgescência.

As medições, feitas em amostras simples, foram iniciadas às $6: 00 \mathrm{~h}$ da manhã do dia seguinte, seccionando-se $1 / 3$ da folha sob água. A fração da fol ha foi envolvida por um filme plástico (magipack), para evitar perdas por evaporação, e submetida à câmara de pressão que continha al godão úmido no fundo, até o aparecimento da primeira exsudação. Com auxílio de um coletor (algodão envolvido em papel absorvente), previamente pesado, enxugou-se a gotícula do suco da superfície cortada, a fim de calcular a quantidade de seiva retirada da fol ha sob aquela pressão inicial da bomba. Esse processo de coleta de seiva foi repetido sucessivamente com acréscimos de pressão de 0,$2 ; 0,3 ; 0,4 ; 0,5 \ldots \mathrm{MPa}$, até atingir em torno de $3 \mathrm{MPa}$.

Após o registro das pressões evol umes coletados, a amostra foi retirada da câmara, pesada imediatamentee levada para secar em estufa $\left(\sim 75^{\circ} \mathrm{C}\right)$ por $48 \mathrm{~h}$. Elaborou-se um gráfico, para cada amostragem, com os val ores do Déficit deSaturação de Água (DSA) nas abscissas e a recíproca das pressões nas ordenadas $(1 / \Psi)$. O DSA é definido pela quantidade de água que a planta ou parte dela requer para a saturação, sendo utilizada para a sua determinação a equação proposta por Klar (1984).

Para calcular a massa de matéria seca e área foliar das plantas, foram observadas três épocas: 55 , 69 e 83 DAE. A área foliar (AF) da planta toda foi estimada por um integrador de área foliar. Para determinar a matéria seca (MS) das várias partes da planta, foram colhidos separadamente, fol has, raízes, col mos, inflor escências e espigas em estufa a $70^{\circ} \mathrm{C}$ para secagem até massa constante. A matéria 
seca total foi estimada pelo somatório das referidas partes. Os teores de cálcio, magnésio e potássioforam determinados nas fol has bandeiras, seguindo método descrito por Bataglia et al. (1983).

Por meio da análise de crescimento (Benincasa, 1988), foram encontrados os seguintes índices fisiológicos: área foliar específica (AFE) em $\mathrm{cm}^{2} \mathrm{~g}^{-1}$, sendo o quociente entre a área foliar e a massa seca defol has; razão demassa fol iar (RMF) em g g-1 , sendo o quociente entre a massa seca de fol has e massa seca total, e a razão de área foliar (RAF) em $\mathrm{cm}^{3} \mathrm{~g}^{-1}$, sendo o quociente entrea área fol iar e a massa seca total.
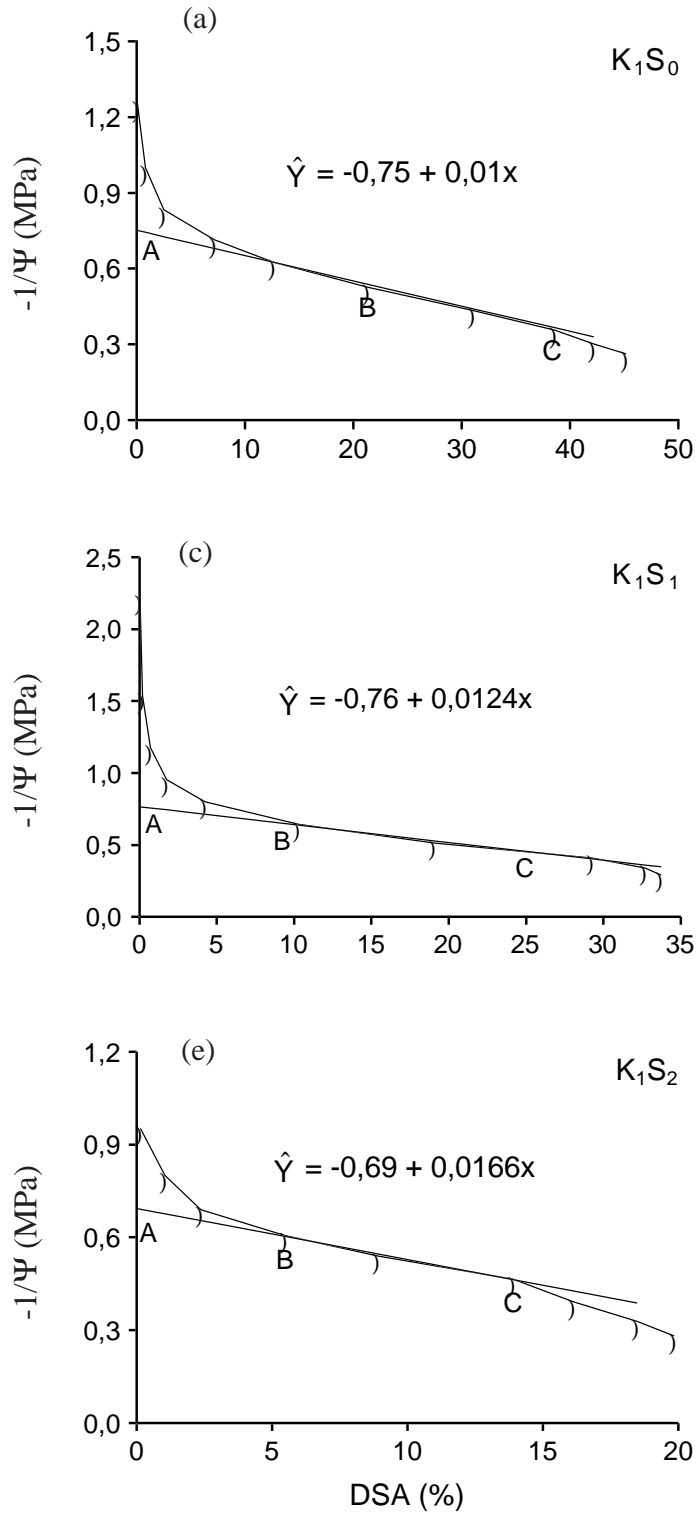

\section{RESULTADOS E DISCUSSÃO}

\section{Potencial osmótico}

Nas curvas pressão-volume, utilizadas para estimar o potencial osmótico na folha (Figura 1), o ponto A representa a projeção da região reta da curva

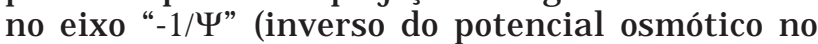
turgor máximo), obtido pela regressão linear do intervalo B-C.

Anal isando os val ores de potenciais osmóticos dos tratamentos, bem como a percentagem de ajuste osmótico dentro das doses de potássio (Quadro 2),

(b)

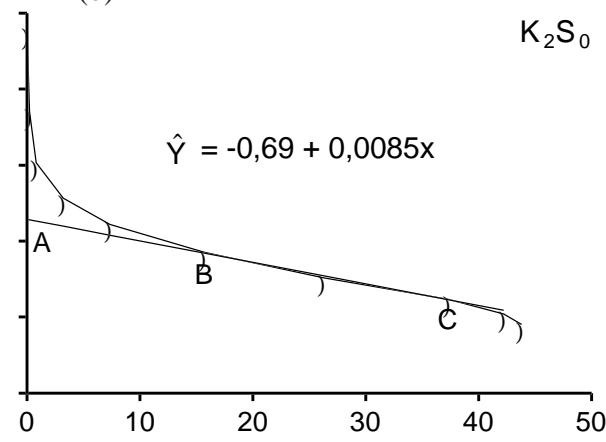

(d)
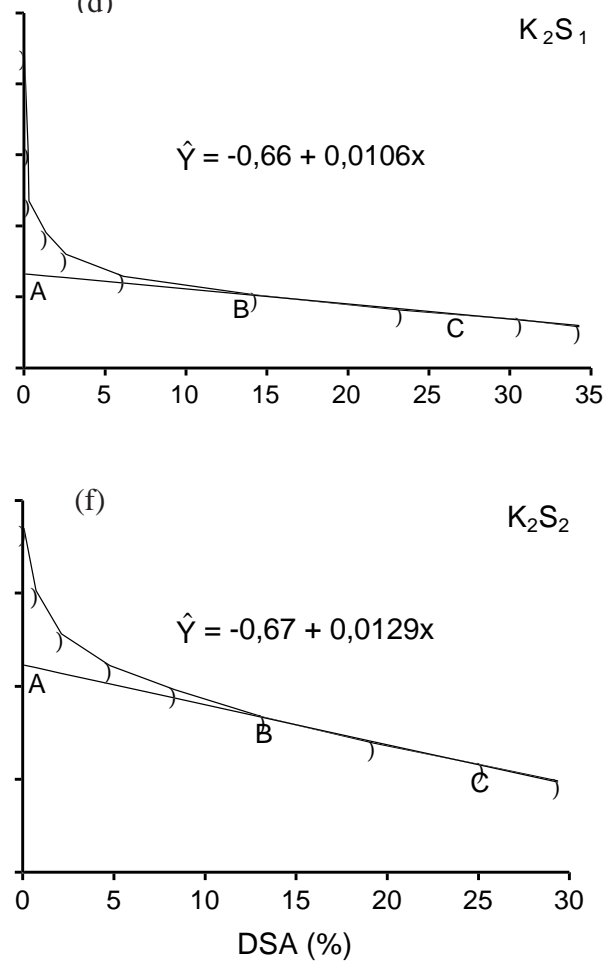

Figura 1. Curvas pressão-volume para o inverso do potencial de água em função do déficit de saturação por água (DSA) para calcular o potencial osmótico (ponto A) na folha de plantas de milho submetidas a duas doses de potássio (K) e três níveis de estresse hídrico (S), 76 a 78 dias após a emergência. 
pode-se observar que a dose de potássio afetou a percentagem deajusteosmótico, dentro de cada nível de estresse hídrico, da seguinte maneira: nos tratamentos irrigados (SO) eque receberam estresse hídrico moderado (S1), houve ajuste osmótico, respectivamente, de $10(0,13 \mathrm{MPa})$ e $15 \%(0,20 \mathrm{MPa})$ dos tratamentos que receberam maior dose de potássio, em relação aos que foram submetidos à menor dose de potássio; nos tratamentos que receberam estresse hídrico intenso, o potássio não causou ajuste osmótico nas fol has das plantas e os baixos potenciais osmóticos encontrados nos dois tratamentos foram, provavel mente, provocados pelo estresse hídrico, independentemente das doses de potássio utilizadas. Os resultados assemel ham-seaos encontrados por Premachandra et al. (1991) e indicam que as plantas de milho podem-se beneficiar de ajuste osmótico em condições de seca moderada, quando bem nutridas em potássio.

Quanto ao efeito do estresse hídrico no ajustamento osmótico das plantas, dentro de cada dose de potássio utilizada, ainda pel o quadro 2, podese verificar que, quando a fertilização potássica foi baixa (K 1), os potenciais osmóticos foram de -1,33; $-1,31$ e $-1,45 \mathrm{MPa}$, respectivamente, para os tratamentos S0, S1 e S2, concluindo-se que houve ajuste osmótico aproximadamente de 11 a $12 \%$ do tratamento S2, em relação aos tratamentos S1 eS0. No entanto, quando se aumentou a dose de potássio (K2), os potenciais osmóticos foram de -1,46; -1,51 e $-1,50 \mathrm{MPa}$, respectivamente, para os tratamentos S0, S1 e S2, não havendo ajuste osmótico entre os tratamentos. Neste caso, o responsável pel os baixos valores de potencial osmótico desenvolvidos nas fol has das plantas foi o potássio, independentemente dos estresses hídricos utilizados.

Estes resultados são semel hantes aos obtidos por Premachandra et al. (1992), que verificaram ocorrer ajuste osmótico de 0,08 a 0,43 MPa em cultivares de milho submetidos a estresse intenso (-1,2 a -1,5 MPa) quando comparados aos submetidos ao estresse

Quadro 2. Valores de potenciais osmóticos e ajuste osmótico de folhas de plantas de milho em função das doses de potássio e do estresse hídrico

\begin{tabular}{lcc}
\hline Tratamento & $\Psi$ & Ajuste osmótico \\
\hline & MPa & $\%$ \\
K 1S0 & $-1,33$ & 10 \\
K 2S0 & $-1,46$ & \\
K 1S1 & $-1,31$ & 15 \\
K2S1 & $-1,51$ & \\
K 1S2 & $-1,45$ & 3 \\
K2S2 & $-1,50$ & \\
\hline
\end{tabular}

moderado (-0,3 a -0,9 MPa). Pinho et al . (1993), avaliando potenciais hídricos nas fol has de plantas de milheto e sorgo pelo método pressão-volume, observaram um ajuste osmótico de 0,1 a 0,3 MPa nas plantas submetidas a um déficit hídrico de 15 dias, em relação às plantas sem estresse.

Pode-se inferir, para as condições estudadas, que o ajustamento osmótico foi provocado pel o potássio ou pelo estressehídrico. As plantas expostas à maior dose de potássio não se beneficiaram de ajuste osmótico para os tratamentos de estresse hídrico e, em relação ao potássio, as plantas submetidas ao maior nível de estresse hídrico não seajustaram em relação às doses de potássio.

\section{Concentração de potássio, cálcio e magnésio}

A análise estatística dos dados (Quadro 3) mostrou que o estresse hídrico não afetou as concentrações de potássio, cál cio e magnésio na fol ha bandeira das plantas de milho, indicando que as freqüências de irrigação nos tratamentos com estresse (S1 ou S2) foram suficientes para garantir teores destes nutrientes nas fol has, comparáveis aos do tratamento irrigado permanentemente (S0).

Anal isando o efeito das doses de potássio sobre o teor foliar deK, pode-seobservar, em todas as épocas, que as plantas que receberam maior dose de potássio (K2) apresentaram teores foliares significativamente maiores dos tratamentos deficientes em potássio (K 1 ). De modo geral, as concentrações foliares de K encontradas para ambos os tratamentos (K 1 ou K2) estão, em todas as épocas, pouco acima do nível crítico

Quadro 3. Concentração de potássio, cálcio e magnésio nas folhas bandeiras de plantas de milho em função das doses de potássio, nas três épocas de coleta

\begin{tabular}{|c|c|c|c|c|c|}
\hline & \multirow{2}{*}{$\begin{array}{l}\text { Dose de } \\
\text { potássio }\end{array}$} & \multicolumn{4}{|c|}{ É poca (dias após emergência) } \\
\hline & & 55 & 69 & 83 & C.V. \\
\hline & & 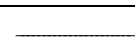 & dag $\mathrm{kg}^{-1}$ & & $\%$ \\
\hline Potássio & $\begin{array}{l}\mathrm{K} 1 \\
\mathrm{~K} 2\end{array}$ & $\begin{array}{l}1,56 b^{(1)} \\
2,06 a\end{array}$ & $\begin{array}{l}1,40 \mathrm{~b} \\
2,18 \mathrm{a}\end{array}$ & $\begin{array}{l}1,47 \mathrm{~b} \\
2,11 \mathrm{a}\end{array}$ & 12 \\
\hline Média & & $2,08 \mathrm{~A}$ & $1,79 \mathrm{~B}$ & $1,79 \mathrm{~B}$ & \\
\hline Cálcio & $\begin{array}{l}\mathrm{K} 1 \\
\mathrm{~K} 2\end{array}$ & $\begin{array}{l}0,42 a \\
0,37 a\end{array}$ & $\begin{array}{l}0,45 \mathrm{a} \\
0,37 \mathrm{~b}\end{array}$ & $\begin{array}{l}0,51 \mathrm{a} \\
0,44 \mathrm{~b}\end{array}$ & 16 \\
\hline Média & & $0,40 \mathrm{~B}$ & $0,42 \mathrm{~B}$ & $0,48 \mathrm{~A}$ & \\
\hline Magnésio & $\begin{array}{l}\mathrm{K} 1 \\
\mathrm{~K} 2\end{array}$ & $\begin{array}{l}0,43 a \\
0,21 \mathrm{~b}\end{array}$ & $\begin{array}{l}0,36 \text { a } \\
0,30 a\end{array}$ & $\begin{array}{l}0,47 \mathrm{a} \\
0,21 \mathrm{~b}\end{array}$ & 28 \\
\hline Média & & $0,29 \mathrm{~B}$ & $0,33 \mathrm{~B}$ & $0,37 \mathrm{~A}$ & \\
\hline
\end{tabular}

(1) Médias seguidas de letras maiúsculas e minúsculas diferentes, respectivamente, na mesma linha e coluna, diferem estatisticamente entre si, pelo teste de Tukey $(p<0,05)$. 
mínimo sugerido por Peaslee \& Moss (1966), entre 1,1 e 1,5 dag kg-1 de K, em condições de vaso. Até os $83 \mathrm{DAE}$, as plantas não apresentaram deficiência visível de potássio em suas fol has, embora a maior dose de potássio tenha levado à maior produção de matéria seca das partes da planta e da planta toda, conforme será descrito posteriormente.

De modo geral, os solos dos tratamentos que receberam maior dose de potássio tiveram menores teores foliares de cálcio e de magnésio. As doses de potássio utilizadas provocaram, na maior parte dos casos, diferenças significativas na concentração de cál cio e demagnésio, dentro da mesma época de col eta.

O teor médio de $0,42 \mathrm{dag} \mathrm{kg}^{-1}$ de cálcio é comparável ao val or de 0,38 dag $\mathrm{kg}^{-1}$ encontrado por Warncke \& Barber (1974) e levemente superior ao de Andrade et al. (1975), que relataram valor de 0,31 dag kg-1 de cálcio.

As concentrações de magnésio na folha, para ambas as doses de potássio, estiveram acima do nível crítico, que, segundo Peaslee \& Moss (1966), está em torno de 0,15 dag $\mathrm{kg}^{-1}$.

\section{Características biométricas e fisiológicas}

A anál ise estatística dos dados revel ou não haver interação dos tratamentos "potássio x água" para as características biométricas avaliadas. Dessa forma, nos quadros 4 e 5, são apresentadas as médias destas características, com relação aos níveis de potássio e de estresse hídrico, respectivamente.
A maior dose de potássio (K2) aumentou a área foliar, significativamente, em 6,7 e 8,6\%, respectivamente, aos 55 e $69 \mathrm{DAE}$, em relação ao tratamento K1 (Quadro 4). Andersen et al. (1992) aplicaram doses de 50, 125 e $200 \mathrm{~kg} \mathrm{ha}^{-1}$ de K, em plantas de cevada, e verificaram que as plantas submetidas ao primeiro tratamento tiveram a área foliar $26 \%$ menor que os outros dois tratamentos. Ferreira (1993), trabal hando com o mesmo cultivar de milho do presente trabalho, não encontrou diferenças significativas entreval ores deárea foliar de plantas submetidas às doses de 90 e $180 \mathrm{mg} \mathrm{kg}^{-1}$ de $\mathrm{K}$; entretanto, tais diferenças foram $42 \%$ superiores às das plantas cultivadas com $12 \mathrm{mg} \mathrm{kg}^{-1}$ de K.

A resposta da massa seca de folhas (MSF) à adubação potássica confirma resultados de Ferrei ra (1993) e Stromberger et al. (1994). Observa-se que, a partir dos $69 \mathrm{DAE}$, não ocorreu ganho significativo de MSF, coincidindo, nesta mesma época, com redução da área foliar das plantas (Quadro 4). Tal comportamento pode ser atribuído ao fato de as fol has secas não estarem sendo computadas na avaliação da área foliar.

O potássio, como estímulo ao crescimento de raízes, col mo e da planta toda, avaliado pel o ganho de massa seca (MST), confirma resultados de Ferreira (1993). E m média, aos 55, 69 e 83 DAE, a massa seca total do tratamento K 2 foi de 17,15 e $15 \%$ significativamentemaior, respectivamente, que a do tratamento K1. Bar-Tal et al. (1991) não

Quadro 4. Área foliar e produção de matéria seca de folhas (MSF), raízes (MSR), colmos (MSC) e total (MST) de plantas de milho em função das doses de potássio, nas três épocas de coleta

\begin{tabular}{|c|c|c|c|c|c|}
\hline & \multirow{2}{*}{ Dose de potássio } & \multicolumn{3}{|c|}{ É poca (dias após emergência) } & \multirow{2}{*}{$\begin{array}{c}\text { C.V. } \\
\%\end{array}$} \\
\hline & & 55 & 69 & 83 & \\
\hline Área foliar, $\mathrm{cm}^{2} /$ planta & $\begin{array}{l}\mathrm{K}_{1} \\
\mathrm{~K}_{2}\end{array}$ & $\begin{array}{l}8521 b^{(1)} \\
9092 a\end{array}$ & $\begin{array}{l}8192 \text { b } \\
8894 a\end{array}$ & $\begin{array}{l}7076 a \\
7273 a\end{array}$ & 7 \\
\hline M édia & & $8806 \mathrm{~A}$ & $8543 \mathrm{~A}$ & $7174 \mathrm{~B}$ & \\
\hline MSF, g/planta & $\begin{array}{l}\mathrm{K}_{1} \\
\mathrm{~K}_{2}\end{array}$ & $\begin{array}{l}32,25 \mathrm{~b} \\
36,94 \mathrm{a}\end{array}$ & $\begin{array}{l}36,34 \mathrm{a} \\
38,43 \mathrm{a}\end{array}$ & $\begin{array}{l}37,89 \mathrm{~b} \\
41,61 \mathrm{a}\end{array}$ & 8 \\
\hline M édia & & $34,59 \mathrm{~B}$ & $37,38 \mathrm{~A}$ & $39,75 \mathrm{~A}$ & \\
\hline MSR, g/planta & $\begin{array}{l}\mathrm{K}_{1} \\
\mathrm{~K}_{2}\end{array}$ & $\begin{array}{l}10,24 \mathrm{a} \\
14,13 \mathrm{a}\end{array}$ & $\begin{array}{l}17,66 \mathrm{ab} \\
20,84 \mathrm{a}\end{array}$ & $\begin{array}{l}16,08 \mathrm{~b} \\
23,35 \mathrm{a}\end{array}$ & 28 \\
\hline M édia & & $12,19 \mathrm{~B}$ & $19,25 \mathrm{~A}$ & $19,71 \mathrm{~A}$ & \\
\hline MSC, g/planta & $\begin{array}{l}\mathrm{K}_{1} \\
\mathrm{~K}_{2}\end{array}$ & $\begin{array}{l}51,27 \mathrm{~b} \\
59,23 \mathrm{a}\end{array}$ & $\begin{array}{l}59,38 \mathrm{~b} \\
71,24 \mathrm{a}\end{array}$ & $\begin{array}{l}75,46 \mathrm{~b} \\
88,76 \mathrm{a}\end{array}$ & 12 \\
\hline M édia & & $55,25 \mathrm{C}$ & $65,31 \mathrm{~B}$ & $82,11 \mathrm{~A}$ & \\
\hline MST, g/planta & $\begin{array}{l}\mathrm{K}_{1} \\
\mathrm{~K}_{2}\end{array}$ & $\begin{array}{l}100,19 \mathrm{~b} \\
117,50 \mathrm{a}\end{array}$ & $\begin{array}{l}131,27 \mathrm{~b} \\
150,53 \mathrm{a}\end{array}$ & $\begin{array}{l}187,53 \mathrm{~b} \\
215,49 \mathrm{a}\end{array}$ & 13 \\
\hline M édia & & $108,84 \mathrm{C}$ & $140,90 \mathrm{~B}$ & $201,51 \mathrm{~A}$ & \\
\hline
\end{tabular}

(1) Médias seguidas de letras maiúsculas e minúsculas diferentes, respectivamente na mesma linha e coluna, diferem estatisticamente entre si, pelo teste de Tukey $(p<0,05)$. 
Quadro 5. Produção de matéria seca de folhas, colmos, raízes e total, de plantas de milho em função dos níveis de estresse hídrico, nas três épocas de coleta

\begin{tabular}{|c|c|c|c|c|}
\hline & \multirow{2}{*}{$\begin{array}{l}\text { Nível de } \\
\text { estresse }\end{array}$} & \multicolumn{3}{|c|}{ É poca (dias após emergência) } \\
\hline & & 55 & 69 & 83 \\
\hline & & & -g/planta & - \\
\hline Folhas & $\begin{array}{l}\text { S0 } \\
\text { S1 } \\
\text { S2 }\end{array}$ & $\begin{array}{l}37,44 a^{(1)} \\
31,09 b \\
35,25 a b\end{array}$ & $\begin{array}{l}40,49 \mathrm{a} \\
35,65 \mathrm{~b} \\
36,02 \mathrm{~b}\end{array}$ & $\begin{array}{l}40,54 a \\
39,97 a \\
38,73 a\end{array}$ \\
\hline Raízes & $\begin{array}{l}\text { S0 } \\
\text { S1 } \\
\text { S2 }\end{array}$ & $\begin{array}{r}14,86 \mathrm{a} \\
11,77 \mathrm{a} \\
9,93 \mathrm{a}\end{array}$ & $\begin{array}{l}25,90 \mathrm{a} \\
16,81 \mathrm{~b} \\
15,05 \mathrm{~b}\end{array}$ & $\begin{array}{l}23,12 a \\
19,07 a \\
16,95 a\end{array}$ \\
\hline Colmos & $\begin{array}{l}\text { S0 } \\
\text { S1 } \\
\text { S2 }\end{array}$ & $\begin{array}{l}66,64 \mathrm{a} \\
49,59 \mathrm{~b} \\
49,53 \mathrm{~b}\end{array}$ & $\begin{array}{l}75,73 \mathrm{a} \\
62,98 \mathrm{~b} \\
57,22 \mathrm{~b}\end{array}$ & $\begin{array}{l}91,56 \mathrm{a} \\
84,27 \mathrm{a} \\
70,49 \mathrm{~b}\end{array}$ \\
\hline Total & $\begin{array}{l}\text { S0 } \\
\text { S1 } \\
\text { S2 }\end{array}$ & $\begin{array}{c}127,91 \mathrm{a} \\
96,62 \mathrm{~b} \\
102,0 \mathrm{~b}\end{array}$ & $\begin{array}{l}173,80 \mathrm{a} \\
129,64 \mathrm{~b} \\
119,26 \mathrm{~b}\end{array}$ & $\begin{array}{l}235,08 \mathrm{a} \\
201,48 \mathrm{~b} \\
167,96 \mathrm{c}\end{array}$ \\
\hline
\end{tabular}

(1) Médias seguidas de letras minúsculas diferentes, na mesma coluna, diferem estatisticamente entre si pelo teste de Tukey $(p<0,05)$.

encontraram diferenças significativas na produção de matéria seca total de plantas de milho, quando submetidas a doses crescentes de potássio.

O efeito do estresse hídrico na produção de massa seca dos componentes e da planta toda pode ser observado no quadro 5. A área foliar da planta não foi influenciada pelos déficits hídricos, sendo este resultado coincidente com Espinoza (1982), mas diferentedos encontrados por NeSmith \& Ritchie(1992).

A produção de massa seca de raízes (MSR) e de massa seca de folhas (MSF) foi semelhante em relação ao estresse hídrico (Quadro 5). Observa-se que as plantas irrigadas constantemente (SO) produziram mais massa do que as dos tratamentos S1 eS2, no entanto, apenas aos 69 DAE, a produção dos tratamentos S0 foi estatisticamente diferente das demais, indicando que nenhuma dessas características, isoladamente, seria adequada para indicar a deficiência hídrica da planta. Não houve correlação entre a massa seca de fol has e a massa seca total, conforme determinado por outros autores. A influência do estresse hídrico causando reduções na densidade de raízes foi encontrada por Andersen et al. (1992), em plantas de cevada; no entanto, resultados contrários foram observados por Espinoza (1982), em plantas de milho.

A massa seca de colmo (MSC) do tratamento $S_{0}$ foi maior e significativamente diferente dos tratamentos submetidos ao estresse hídrico aos 55 e 69 DAE (Quadro 5). Aos 83 DAE, a MSC do tratamento S1 igualou-se estatisticamente à do tratamento S0, fato, provavelmente, devido ao transporte de assimilados dos colmos para as espigas nesteúltimo tratamento, queteve, nesta época, 40 e 94\% a mais de massa seca de espiga, respectivamente, com relação aos tratamentos S1 $(53,5 \mathrm{~g})$ e $\mathrm{S} 2(38,5 \mathrm{~g})$.

Considerando o efeito do estresse hídrico na produção de matéria seca total (MST), verifica-se que, a partir dos $55 \mathrm{DAE}$, os tratamentos sem deficiência hídrica (S0) foram sempre superiores e estatisticamente diferentes de S1 e S2, parecendo ser esta característica adequada para avaliar o efeito do estresse hídrico na cultura do milho. Aos 83 DAE, ocorreu diferença significativa entre todos os tratamentos, havendo diferenciação até entre os tratamentos submetidos ao estresse hídrico. Nesta última época, a MST dos tratamentos S1 e S2 foi, em média, de 14,3 e 28,6\% menor, respectivamente, que a do tratamento-controle (SO).

A análise de variância dos índices fisiológicos mostrou serem eles influenciados pelas doses de potássio. No quadro 6, são apresentadas somenteas médias relativas ao efeito dos níveis de estresse hídrico aplicados em todas as épocas estudadas.

Pôde-se observar anteriormente que os níveis de estresse hídrico não afetaram a área foliar das plantas, sendo então a matéria seca das fol has a componente responsável pela variação na AFE, causando reduções nesteíndice quando do aumento desta. O aumento ou diminuição da AFE não foi definido pel o decréscimo da umidade, notando-seque as plantas irrigadas constantemente tiveram os menores valores deAFE. Contrariamente, a AFE dos tratamentos S1 tiveram maiores val ores do que S2, seguindo o comportamento da MST. Reduções na AFE, com oaumento da disponibilidade deágua para a planta, são contrárias aos resultados encontrados por Premachandra et al. (1991). Houve tendência de decréscimo da AFE com o desenvolvimento da cultura, sendo relatado na literatura controvérsia sobre o comportamento deste índice fisiológico em relação ao tempo, podendo este variar com a espécie vegetal, condições experimentais e método de cál culo (Netto, 1993).

A razão de massa foliar (RMF) também decresceu, aolongo do cicl ofenológico, coincidindo com resultados apresentados pela literatura, que relatam valores elevados de RMF no início do ciclo vegetativo e, posteriormente, decréscimo, em função do direcionamento dos compostos fotossintetizados para outras regiões da planta (Netto, 1993). O quadro 6 mostra, em todas as épocas, que as plantas submetidas a estresse hídrico intenso tiveram os valores de RMF significativamente maiores que os das plantascontrole (S0), sugerindo menor exportação de assimilados da fol ha para outros órgãos da planta. 
Quadro 6. Valores médios de área foliar específica (AFE), razão de massa foliar (RMF) e razão de área foliar (RAF) de plantas de milho em função dos níveis de estresse hídrico, nas três épocas de coleta

\begin{tabular}{|c|c|c|c|c|c|}
\hline & \multirow{2}{*}{ Nível de estresse } & \multicolumn{3}{|c|}{ É poca (dias após emergência) } & \multirow{2}{*}{ Média } \\
\hline & & 55 & 69 & 83 & \\
\hline \multirow{3}{*}{ AFE, $\mathrm{cm}^{2} \mathrm{~g}^{-1}$} & so & $242,2 \mathrm{~b}$ & $214,8 a$ & 174,8 a & $209,6 \mathrm{~b}$ \\
\hline & S1 & $286,4 a$ & 244,3 a & 186,9 a & 239,2 a \\
\hline & S2 & $248,1 \mathrm{~b}$ & 229,5 a & 182,0 a & $219,9 a b$ \\
\hline \multirow[t]{2}{*}{ Média } & & $258,9 \mathrm{~A}$ & $229,6 \mathrm{~B}$ & $181,2 \mathrm{C}$ & \\
\hline & so & $0,30 \mathrm{~b}$ & $0,24 \mathrm{~b}$ & $0,18 \mathrm{~b}$ & $0,23 c$ \\
\hline \multirow{2}{*}{$R M F, g^{-1}$} & S1 & $0,33 \mathrm{ab}$ & $0,28 a b$ & $0,20 \mathrm{ab}$ & $0,26 \mathrm{~b}$ \\
\hline & s2 & 0,35 a & $0,30 \mathrm{a}$ & $0,23 a$ & $0,29 a$ \\
\hline \multirow[t]{2}{*}{ Média } & & $0,32 \mathrm{~A}$ & $0,27 \mathrm{~B}$ & $0,20 \mathrm{C}$ & \\
\hline & so & $72,2 \mathrm{~b}$ & $51,6 \mathrm{~b}$ & 30,4 a & $51,3 \mathrm{~b}$ \\
\hline \multirow{2}{*}{ RAF, $\mathrm{cm}^{2} \mathrm{~g}^{-1}$} & S1 & 91,2 a & $69,1 \mathrm{a}$ & $36,9 a$ & $65,8 \mathrm{a}$ \\
\hline & S2 & 86,6 a & 69,5 a & 41,9 a & 66,1 a \\
\hline Média & & $83,3 \mathrm{~A}$ & 63,4 B & $36,6 \mathrm{C}$ & \\
\hline
\end{tabular}

(1) Médias seguidas de letras maiúsculas e minúsculas diferentes, respectivamente na mesma linha e coluna, diferem estatisticamente entre si pelo teste de Tukey $(p<0,05)$.

Tal como o exposto para a AFE, a razão de área foliar (RAF) foi reduzida com o aumento do fornecimento de água, refletindo o efeito desse tratamento na produção de matéria seca total. Analisando essa característica dentro dos tratamentos que sofreram deficiência hídrica, observa-se que não há definição de aumento ou redução que caracteriza tal índice, sendo este variável com a época. Urchei (1992) encontrou uma tendência à diminuição da RAF, em plantas de cevada, sob condições de déficit hídrico, conseqüência de alterações sofridas, sobretudo, na área foliar da RAF. A RAF decresceu, ao longo do tempo, coincidindo com resultados de Machado et al . (1982).

\section{CONCLUSÕES}

1. As fol has das plantas de milho se ajustaram osmoticamente em relação às doses de potássio, em condições de estresse hídrico moderado, no entanto este ajuste não causou diferenças significativas quando se avaliou o crescimento da planta por meio da análise de matéria seca.

2. A adição depotássionão mel horou ocrescimento da cultura na condição severa de estresse hídrico, no entanto, as plantas mais bem nutridas em potássio produzi ram mais massa seca, independente dos níveis de água utilizados.

3. A produção de matéria seca total foi a característica que melhor refletiu os efeitos do déficit hídrico nas plantas.

\section{LITE RATURA CITADA}

ANDERSEN, M.N.J ENSEN, C.R. \& LÖSCH, R. Theinteraction effects of potassium and drought in field-grown barley. I. yield, water-use efficiency and growth. Soil Plant Sci., 42:3444, 1992.

ANDRADE, A.G.; HAAG, H.P.; OLIVEIRA, G.D. \& SARRUGE, J .R. Acumulação diferencial de nutrientes por cinco cultivares de milho (Zea mays L.). I- Acumulação de macronutrientes. An. ESALQ, 23:115-149, 1975.

ASSAD, E.D.; SANO, E.E.; MASUTOMO, R.; CASTRO, L.H.R. \& SILVA, F.A.M. Veranicos na região dos cerrados brasilei ros freqüência e probabilidade de ocorrência. Pesq. Agropec. Bras., 28:993-1003, 1993.

BATAGLIA, O.C.; FURLANI, A.M.C.; TEIXEIRA, J.P.F.; FURLANI, P.R. \& GALO, J .R. Métodos de análise química de plantas. Campinas, Instituto Agronômico, 1983. 48p. (Boletim Técnico, 68)

BAR-TAL, A.; FEIGENBAUM, S. \& SPARKS, D.L. Potassiumsalinity interactions in irrigated corn. I rrig. Sci., 12:27-35, 1991.

BENINCASA, M.M.P. Análise de crescimento de plantas, J aboticabal, FUNEP, 1988. 42p.

EMPRESA BRASILEIRA DE PESQUISA AGROPECUÁRIA EMBRAPA. Serviço Nacional de Levantamento e Conservação do Solo. Critérios para distinção de classes de sol os e de fases de unidades de mapeamento - Normas em uso pelo SNCLS. Rio de J aneiro, 1988. 67p. 
ESPINOZA, W. Resposta de doze cultivares de milho ao déficit hídrico num Latossolo Vermel ho-Escuro (typic haplus tox) decerrados do DistritoF ederal. Pesq. Agropec. Bras., 17:905915, 1982.

FERREIRA, E. Características fisiológicas, absorção de nutrientes e desenvolvimento de plantas de milho (Zea mays L.) em função do nível de potássio e estresse hídrico. Botucatu, UNESP, Faculdade de Ciências Agronômicas, 1993. 130p. (Tese de Mestrado)

KLAR, A.E. A água no sistema solo-planta-atmosfera. São Paulo, Nobel, 1984. 408p.

MACHADO, E.C.; PEREIRA, A.R.; FAHL, J .I .; ARRUDA, H.V.; SILVA, W.J . \& TEIXEIRA, J.P.F. Análise quantitativa de crescimento de quatro variedades de milho em três densidades de plantio, através de funções matemáticas ajustadas. Pesq. Agropec. Bras., 17:825-833, 1982.

NeSMITH, D.S. \& RITCHIE, J.T. Short-and. Long Term Responses of corn to a Pre-Anthesis Soil water Deficit. Agron. J ., 84:107-113, 1992.

NETTO, A.O.A. Comportamento fisiológico e produtivo da ervilha (Pisium sativum L.), submetida à diferentes potenciais água no solo. Botucatu, Universidade Estadual Paulista, 1993. 151p. (Tese de Mestrado)

PEASLEE, D.E. \& MOSS, D.N. Photosynthesis in K and Mg deficient maize (Zea mays L.) leaves. Soil Sci. Soc. Am. Proc., 30:220-223, 1966.

PINHO, J.L.N.; LAFFRAY, D. \& LOUGUT, P. Evolução do ajustamento osmótico em cultivares de sorgo e milheto submetidas ao estresse hídrico. R. Bras. Fisiol. Veg., 5:58, 1993.
PREMACHANDRA, G.; SANEOKA, H. \& OGATA, S. Cell membrane stability and leaf water relations as affected by potassium nutrition of water-stressed maize. J . Exp. Bot., 42:739-745, 1991.

PREMACHANDRA, G.S.; SANEOKA, H.; FUJ ITA, K. \& OGATA, S. Osmotic adjustment and stomatal response to water deficits in maize. J . Exp. Bot, 43:1451-1456, 1992.

RAIJ , B. van \& QUAGGIO,J .A. Métodos de análise de solos para fins de fertilidade. Campinas, Instituto Agronômico, 1983. 31p. (Boletim Técnico, 81)

SHARP, R.E.; HSIAO, T.C. \& SILK, W.K. Growth of the maize primary root at low water potencials. Plant Physiol., 93:1337-1346, 1990

STROMBERGER, J .A., TSAI, C.Y. \& HUBER, D.M. I nterations of potassium with nitrogen and their influence on growth and yield potential in maize. J . Plant Nutr., 17:19-37, 1994.

TYREE, M.T. \& HAMMEL, H.T. The measurement of theturgor pressure and the water relations of plants by the pressure bomb techinique. J . Exp. Bot., 23:267-262, 1972.

URCHEI, M.A. Efeitos de déficits hídricos, em três estádios fenológicos, da cultura da cevada (Hordeum vulgare L.). Botucatu, Universidade Estadual Paulista, 1992. 165p. (Tese de Mestrado)

VIEIRA, S.R. \& CASTRO, O.M. Determinação, em laboratório, de curvas de retenção de água com tensiômetros. R. Bras. Ci. Solo, 11:87-90, 1987.

WARNCKE, D.D. \& BARBER, S.A. Root development and nutrient uptake by corn grown in solution culture. Agron. J., 66:514-516, 1974. 